\title{
Ancient high-carbon steel from southern Tamil Nadu, India: microstructural and elemental analysis
}

\author{
Amit Kumar Singh ${ }^{1}$, Alok Kumar Kanungo ${ }^{1,2}$, V. Selvakumar ${ }^{3}$ and \\ Amit Arora ${ }^{1, *}$ \\ ${ }^{1}$ Indian Institute of Technology Gandhinagar, Palaj, Gandhinagar 382 355, India \\ ${ }^{2}$ College of Humanities, Arts and Social Sciences, Flinders University, Adelaide 5001, Australia \\ ${ }^{3}$ Department of Maritime History and Marine Archaeology, Tamil University, Thanjavur 613 010, India
}

\begin{abstract}
There have been claims of early use of high-carbon steel in South India. Still, the antiquity, elemental composition and steelmaking process have not been explored adequately. The high carbon steel was known in the Iron Age or early historical period. However, the large-scale use of such steel was prevalent only in the medieval times. This article examines the presence of steel and its metallographic features in the iron artifacts retrieved from two archaeological sites, namely Ambal and Vallam, Tamil Nadu, India, with occupational evidence from the Iron Age to the medieval period through a number of scientific tests. Metallographic as well as mechanical tests were performed to identify the morphology and measure the strength respectively. Similarly, the chemical composition was determined to quantify the alloying elements in the material. The slag was exposed on the etched surface of the sample cut from axe. Microscopy and chemical composition analysis showed very fine bright dendrites of wüstite in the iron slag. The deterioration of samples was confirmed in microscopic and composition analysis. The result shows that the inhabitants of ancient Ambal and the Vallam were equipped with iron smelting technology and had the knowledge of steelmaking in the Iron Age.
\end{abstract}

Keywords: Chemical composition, high-carbon steel, iron slag, mechanical test, microstructure.

THROUGHOUT history, knowledge of iron has been chosen as one of the markers of urbanization and cultural development in human civilization. The iron objects are used for various purposes, such as agriculture and carpentry tools, weapons and household utensils. There have been many examples of the use of high carbon Indian crucible steel in the manufacture of various iron artifacts, such as the Delhi Iron Pillar (c. 400-420 CE $)^{1}$ and Damascus sword $(c .1100 \mathrm{CE})^{2}$. The cultural sequence of Bronze Age and Iron Age between 3000 BCE and mid first millennium BCE is fairly categorized for North India and

*For correspondence. (e-mail: amitarora@iitgn.ac.in) well-studied in the literature ${ }^{3,4}$. Though there has been evidence of the smelting of iron ore to make iron in South India ${ }^{5,6}$, the antiquity of steel and indigenous iron metallurgy in this region has been a subject of discussion.

The steelmaking process includes the smelting of iron ore and control of alloying elements during the process. Moreover, thermo-mechanical treatments are induced to improve the strength of the iron or steel objects. Numerous methods such as crucible steel, bloomery process and blast furnace technology are mentioned in the literature to produce cast iron and steel with a low to high percentage of carbon ${ }^{7}$. In general, production of iron and steel is classified under two major categories: direct and indirect methods. In the direct method, the iron ore is reduced (crucible and bloomery process) below its melting point using reducing agents like carbon or charcoal. In ancient times, the bloomery process was often used to obtain iron. The melting point of pure iron, viz. $1535^{\circ} \mathrm{C}$ is reduced to around $1200^{\circ} \mathrm{C}$ by adding $2.1 \mathrm{wt} \%$ of carbon. The smelting of iron ore is performed inside the furnace after making alternate layers of ore and charcoal up to $0.3-$ $0.5 \mathrm{~m}^{3}$ and burning the hardwood charcoal to generate the required heat ${ }^{8}$. Air is continuously supplied inside the furnace with the help of large bellows attached to claymade tuyeres. The product formed called bloom consists of trapped slag and inclusion inside the pores of the reduced bloom. Therefore, the bloom is continuously hammered in the hot state to remove the slag and the unburnt fuelled charcoal, and reduce the porosity. The hammering of bloom modifies the shape of the product with ultrafine grain microstructure. Bloomery processed product has a relatively lower percentage of carbon than the blast furnace technology. However, the percentage of carbon in the bloomery process (wrought iron $<0.1 \%$ and steel $0.1-$ $2.0 \%$ ) is further changed during the heat treatment process to make iron harder by introducing carbon in iron by the carburizing process 9 . Similarly, the steels smelted in a crucible made of clay and ash were called crucible steel. Iron ore was reduced to form slag and iron by heating with charcoal, ash, glass and fluxes. The Indian crucible steel, also called wootz steel, was popular among the 
warriors because of its utility, and among scientists and historians for decades for the science behind its production and its antiquity. In the case of indirect methods like the blast furnace method, higher temperature and reducing environment are reached, resulting in the formation of cast iron with $2.0-4.0 \mathrm{wt} \%$ of carbon.

The origin for the production of high carbon steel is veiled in obscurity ${ }^{10}$. Knowhow of ancient iron smelting technique in South India is a matter of debate ${ }^{7}$. Therefore, various objects and slags found during excavations were analysed using the microstructural and chemical analysis technique to study ancient iron metallurgy in South Asia. The analysis of objects is valuable as it reveals the technique, equipment and raw materials used to manufacture the objects. Similarly, slag analysis reveals properties similar to the final product, and slags are abundantly available near the sites as discard ${ }^{11}$. Banerjee ${ }^{12}$ and Chakrabarti $^{13}$ suggested that the origin of high carbon steel in South Asia could be from both external as well as indigenous sources. The role of Aryans (Indo-Europeanspeaking people) in spreading the knowledge of iron in the subcontinent has been discussed by Shaffer ${ }^{14}$. Evidence of early iron mining, excavation and manufacturing technology in the Indian subcontinent is discussed by Tewari ${ }^{15}$. The comparative analysis of different excavated objects from both North and South India shows remarkable differences in the origin of iron ${ }^{16}$. In North India, iron objects were retrieved from residential sites, whereas in South India they were mostly recovered from the mortuary sites. A number of high carbon steel specimens have also been unearthed in the Deccan region, including Andhra Pradesh, Tamil Nadu and Karnataka, confirming the availability of high-carbon steel in southern India ${ }^{17-19}$. Park et al. $^{20}$ studied the double-edged iron sword made of high carbon steel, which indicated crucible steelmaking in the Thelunganur region of Tamil Nadu, India. High carbon steels were widely used in this region, as shown by numerous scientific studies ${ }^{21,22}$. Similarly, the existence of wind-powered iron smelting technique in Sri Lanka and iron slag near the Khasi Hills, Meghalaya, NE India shows evidence of iron smelting in Sri Lanka and India respectively ${ }^{8,23}$. There have been limited studies in identifying the antiquity of steelmaking in South India. The absence of contextual samples for analysis, and the synergy between the metallurgists and archaeologists in India have compounded such initiatives. Besides, it is a challenge to detect the actual composition of samples because most of the time the iron artifacts are recovered with layers of encrustations. Once retrieved from under the earth, they corrode fast. For most of the analyses, samples need to go through various preparation stages like cutting, grinding and polishing. This invariably requires a piece of core, non-corroded metal and non-rusted corners.

In the present study, the characterization of iron objects like axe and other metallic specimens (mostly slag) obtained from Ambal and Vallam, Tamil Nadu, India, has been carried out using microscopy, phase analysis, mechanical testing and elemental composition studies. These samples have been analysed to evaluate the percentage of carbon which proves the existence of knowledge of high carbon steel. First, the composition of as-received samples was analysed using the X-ray fluorescence (XRF) elemental analysis technique, which requires no preparation of samples. The microstructures of the specimens were studied using optical and electron microscopy techniques. The mechanical characterization of the samples was done using Vickers hardness testing. The energy dispersive X-ray (EDX) spectroscopy was used to detect the phases present in the samples. The samples for optical and electron microscopy, hardness and EDX were prepared following the metallographic polishing and etching.

\section{Study sites}

The present study area is southern Tamil Nadu, the region south of River Kaveri (Figure $1 a$ ). Humans have colonized this region from pre-historic times ${ }^{24-31}$. The Tamil University, Thanjavur excavated the archaeological sites of Vallam, Nagapattinam and Ambal, and the Archaeological Survey of India excavated Therazhundur. These studies have resulted in establishing the cultural chronology and culture contact of the ancient inhabitants. The study also shows that Tamil culture had spread to the neighbouring island country of Sri Lanka. This study deals with iron artifacts retrieved from two sites, viz. Ambal and Vallam. These two sites are close to the Bay of Bengal (west of $79^{\circ} 50^{\prime} \mathrm{E}$ ); this strategic location played a major role in trade and culture contact.

\section{Ambal}

The site of Ambal $\left(10^{\circ} 56^{\prime} 53.58^{\prime \prime} \mathrm{N} ; 7^{\circ} 42^{\prime} 12.65^{\prime \prime} \mathrm{E}\right)$ is located in Nagapattinam district (border of Tiruvarur) and was excavated under the directorship of Selvakumar ${ }^{32}$ in 2015-16. The site has been inhabited from Iron Age until the modern times, through early historic, early medieval and late medieval periods. Throughout these periods, it has yielded a good number of iron and copper implements. One of the early objects, viz. axe was found in the lowermost layer at the site, i.e. the Iron Age (Figure $1 b$ ). Two crucibles used for possible copper working were also found in the early medieval period (Figure $1 \mathrm{c}$ ).

\section{Vallam}

The site of Vallam $\left(10^{\circ} 42^{\prime} 50.4^{\prime \prime} \mathrm{N} ; 79^{\circ} 4^{\prime} 12.72^{\prime \prime} \mathrm{E}\right)$ in Thanjavur district was excavated under the directorship of Subbarayalu ${ }^{33}$. 

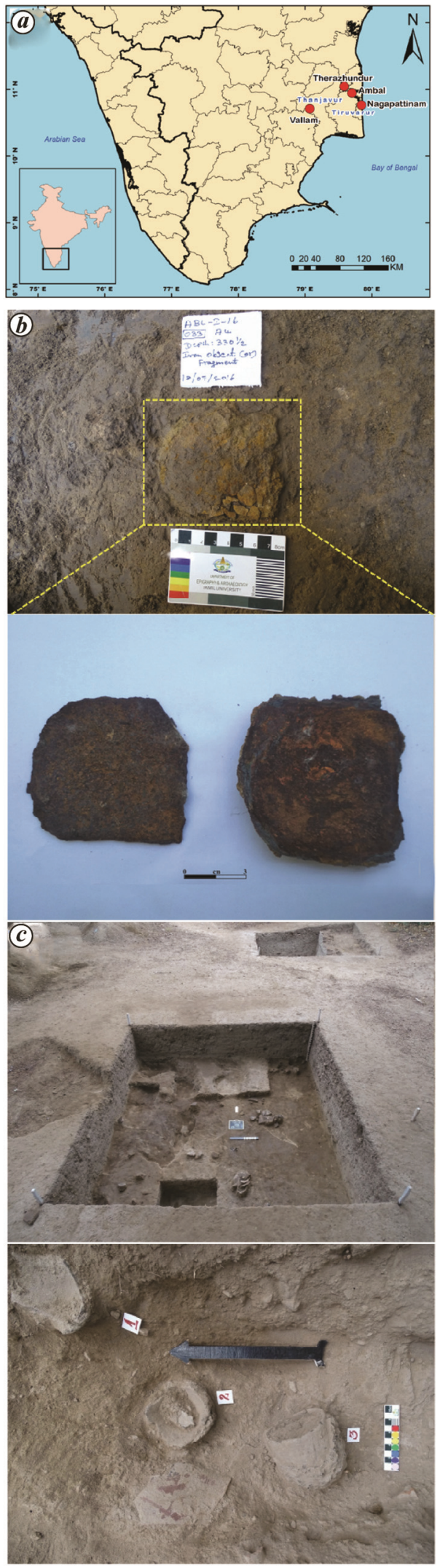

Figure 1. $\boldsymbol{a}$, Map of southern Tamil Nadu, India, showing the referred excavated archaeological sites. $\boldsymbol{b}$, In situ iron axe in Iron Age period, and axe and the crust of the same in the repository. $c$, The excavated early medieval layer and the in situ crucibles for possible copper working.

\section{Specimens and methods}

The specimens such as axe $(\mathrm{AM} / 1)$ and iron objects $(\mathrm{AM} / 2, \mathrm{AM} / 3$ and $\mathrm{VM} / 1)$ were recovered from two habitation sites of Ambal and Vallam. Table 1 provides the sample details, associated dates and conditions of the samples. These samples were from three different periods, i.e. Iron Age, early medieval and medieval age. Figure $2 a-d$ shows the physical appearance of the samples before mounting for further analysis. The arrows in the figure indicate the cross-section where grinding and polishing were done before microscopy and mechanical testing. Sample AM/1 was a core part of the axe and cut from the corner of the sharp edge, as indicated by the arrows in Figure $2 a$. Before mounting, these samples were analysed using an XRF spectrometer (PANalytical Epsilon1, UK) to determine the chemical composition. Then the samples were cold-mounted in epoxy resin and polished using SiC papers of 120, 200, 400, 600, 800 and 1200 grit size. The cloth polishing was done using water suspension of $5 \mu \mathrm{m}$ alumina powder. The mirror-finished polished samples were chemically etched with Nital (10 $\mathrm{ml}$ nitric acid mixed with $90 \mathrm{ml}$ ethanol) at room temperature for $60 \mathrm{~s}$. The etched samples were washed under running water and ethanol, and observed under the optical microscope (OLYMPUS BX51, Japan) to determine the microstructure. The samples were analysed under a field-emission scanning electron microscope (FESEM; JEOL JSM7600F, Japan) in the backscattered electron mode at $10 \mathrm{kV}$ voltage and $48.60 \mu \mathrm{A}$ probe current before and after chemical etching to detect different phases. EDX attached with SEM was used at $15 \mathrm{~mm}$ working distance and $15 \mathrm{kV}$ voltage to confirm the different phases. The microhardness of the polished samples was measured at $500 \mathrm{~g}$ load for $15 \mathrm{~s}$ using the Vickers microhardness indenter. The indenter was placed at the core of the samples to collect the numerous hardness

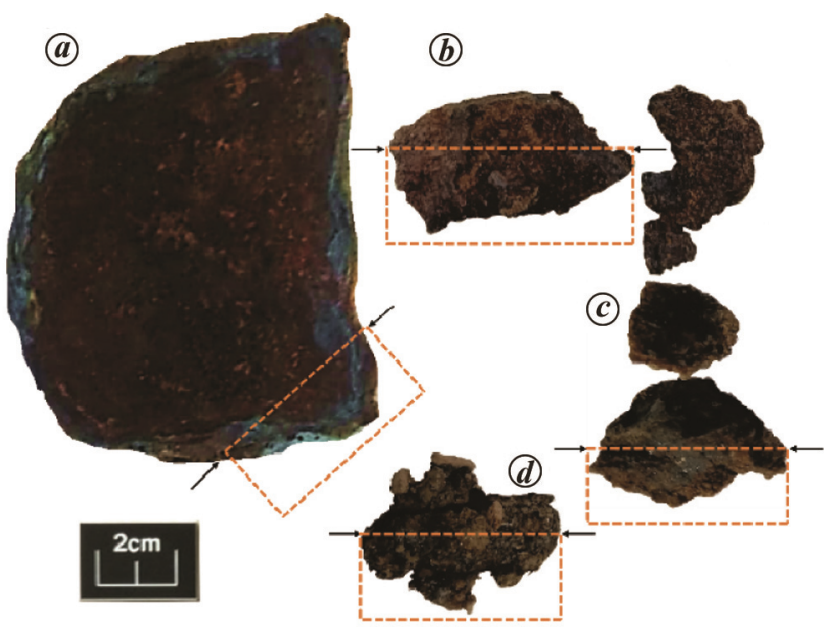

Figure 2. $\boldsymbol{a}, \mathrm{AM} / 1 ; \boldsymbol{b}, \mathrm{AM} / 2 ; \boldsymbol{c}, \mathrm{AM} / 3 ; \boldsymbol{d}, \mathrm{VM} / 1$. Arrow and box show the plane of grinding and polishing. 
Table 1. Summary of different samples collected for the analysis ${ }^{24-31}$

\begin{tabular}{|c|c|c|c|c|c|c|c|}
\hline Sample & Artefact & Site & Period & Date & Rationale of date & $\begin{array}{c}\text { Length of } \\
\text { sample received } \\
(\mathrm{cm})\end{array}$ & Comments \\
\hline $\mathrm{AM} / 1$ & Axe & Ambal & Iron Age & $\begin{array}{l}\text { Mid 1st } \\
\text { millennium BCE }\end{array}$ & $\begin{array}{l}\text { The sample was found in the } \\
\text { lowermost strata of the } 1 \mathrm{~m} \\
\text { thick layer producing } \\
\text { typical Iron Age black and } \\
\text { red ware. A date of } 109- \\
146 \text { cal BC (IUACD\#18C } \\
1823 \text { ) is obtained from a } \\
\text { distinct early historical } \\
\text { cultural layer above this. }\end{array}$ & 8 & Rusted \\
\hline $\mathrm{AM} / 2$ & Iron object & Ambal & $\begin{array}{c}\text { Early } \\
\text { medieval }\end{array}$ & $10-13 c . \mathrm{CE}$ & $\begin{array}{l}\text { The existence of Ambal is } \\
\text { known from various } \\
\text { inscriptions attributed to } \\
\text { the period, including } \\
\text { Brahmapuriswara Siva } \\
\text { temple stone inscriptions } \\
\text { dated to the Chola period. } \\
\text { The period yielded Chola } \\
\text { coins too. }\end{array}$ & 3 & Cracks and rusted \\
\hline $\mathrm{AM} / 3$ & Iron object & Ambal & & $7-10 c . \mathrm{CE}$ & & 2 & Rusted \\
\hline $\mathrm{VM} / 1$ & Iron object & Vallam & $\begin{array}{l}\text { Period III } \\
\text { medieval }\end{array}$ & $15-18 c . \mathrm{CE}$ & $\begin{array}{l}\text { Coincides with the rule of the } \\
\text { Nayakas and the Marathas. }\end{array}$ & 2 & $\begin{array}{l}\text { Encrustated } \\
\text { with non-metals }\end{array}$ \\
\hline
\end{tabular}

values (at least 10), and the standard deviation was calculated.

\section{Results and discussion}

\section{$X R F$ analysis}

The samples were analysed using XRF. Figure $3 a-d$ shows details of composition (in wt \%). Although XRF is not a reliable technique to obtain the elemental composition, we have used it to get an approximate idea regarding the composition before cutting samples. Iron shows up as a major element for each sample in the XRF analysis. Therefore, it is confirmed that the samples are ferrous $(\mathrm{Fe})$. Carbon and phosphorus are the primary alloying elements in iron, which are also reported by Sukhanov et $a l .^{34}$. The XRF plot shows that each sample contains iron and phosphorus, which are the main elements for iron and steel (Figure 3). The percentage of carbon is not shown due to the limitation of the XRF analysis. Other elements (non-metals $\mathrm{Na}, \mathrm{Cl}, \mathrm{Ca}$ ) present in the sample as impurity during excavation are also observed in the XRF bar graph.

\section{Microstructural analysis}

The optical microstructure of the specimen is shown in Figure $4 a$ for sample AM/1 (axe). Figure $4 a$ shows the region in the microstructure of the material etched with
Nital. The microstructure reveals that specimen AM/1 is made using high carbon steel. Figure $4 a$ shows randomly oriented morphology with three-dimensional shapes such as plate, lath and sheet. The randomly oriented pattern and ultra-fine microstructure indicate that the specimen is introduced with severe thermo-mechanical processing during product manufacture or production of iron. It is also observed from Figure $4 a$ that various inclusions and slags are trapped inside the microstructure in rod and round shape. Figure $4 a$ shows that the rod-shaped inclusions are oriented in the horizontal direction and the loading/hammering during processing is vertical. The bloomery process produces a variety of similar iron and steel objects, as illustrated in the literature ${ }^{35}$. The inclusion and slag are generally trapped inside the bloom, and need continuous hammering to remove the slag and unburnt charcoal fuel. Therefore, the analysis suggests that the axe was perhaps made using steel which was a product of the bloomery process.

Similarly, the microstructure from an optical microscope for the samples AM/2, AM/3 and VM/1 is shown in Figure $4 b-d$ respectively, in the polished and etched condition (Nital). Pits, micro-cracks and foreign particles can be seen in each sample, which shows their degraded state loaded with foreign particles. For sample AM/2 (Figure $4 b$ ), the microstructure shows the network of foreign particles with metal, including voids. However, the structure observed in the rectangular box reveals the solidification microstructure. Similarly, Figure $4 c$ shows the columnar solidification morphology in sample AM/3. 
This structure is similar to that found in the cast and solidified steels. Sample VM/1 also shows a similar alternate columnar structure (Figure $4 d$ ).

\section{Phase analysis}

A detailed analysis of different samples was done using FE-SEM and EDX techniques to reveal the microstructure and phases present inside the specimen. The mirrorfinished polished samples were observed under FE-SEM without etching (Figure $5 a-d$ ). Figure $5 a$ shows the photomicrograph of sample AM/1, which contains trapped oxide and slag inside the iron matrix. The alignment of
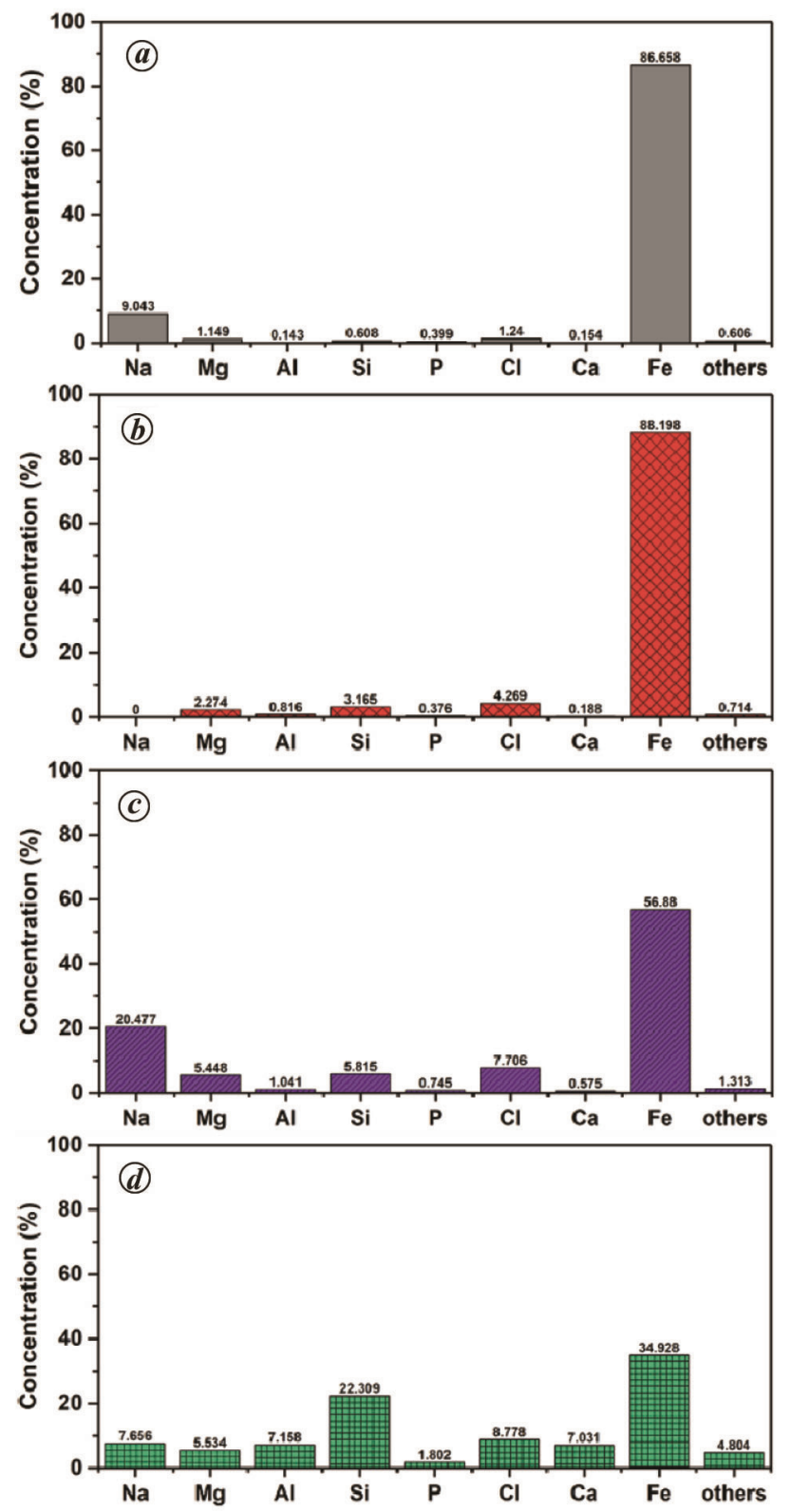

Figure 3. XRF plot showing $w t \%$ of different elements in as-received samples for (a) AM/1, (b) AM/2, (c) AM/3 and (d) VM/1. rod-shaped inclusion in a particular direction indicates the thermo-mechanical processing which the axe might have undergone during manufacture. Very fine spherical pinholes are also observed in the microstructure. This could be the result of the trapped slag and unburnt

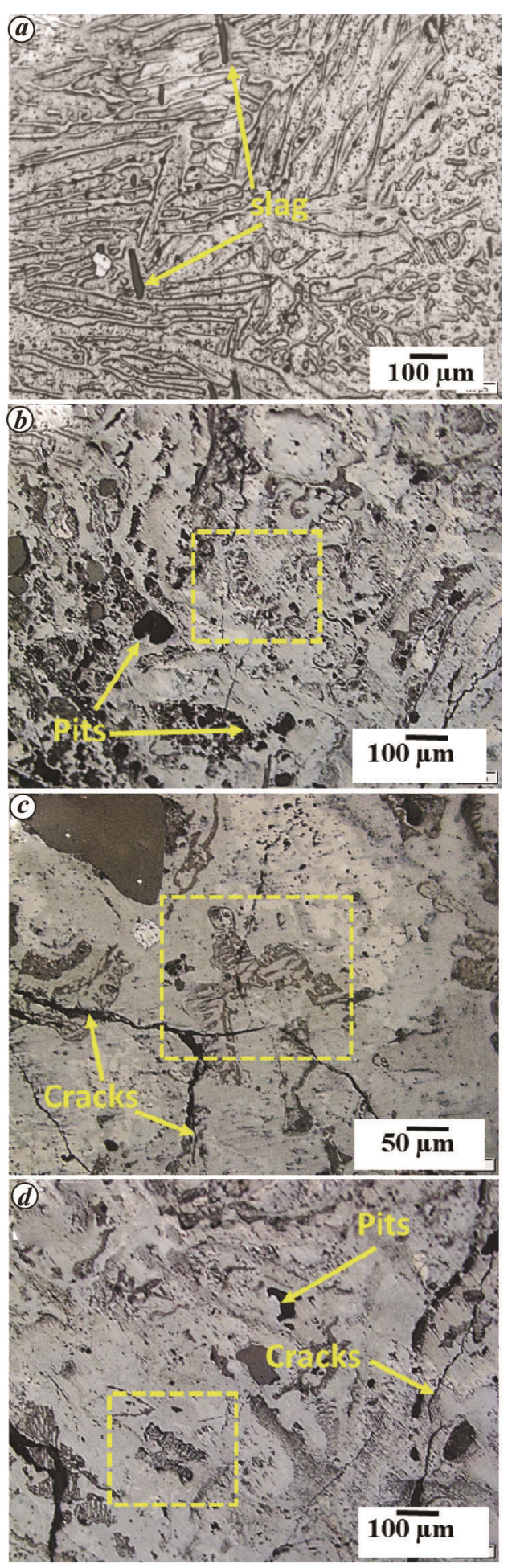

Figure 4. Optical photomicrograph showing the microstructure of (a) $\mathrm{AM} / 1,(\boldsymbol{b}) \mathrm{AM} / 2,(\boldsymbol{c}) \mathrm{AM} / 3$ and (d) $\mathrm{VM} / 1$ etched with Nital. 


\section{RESEARCH ARTICLES}

charcoal as the secondary phase inside the specimen during the bloomery process. Figure $5 b$ shows the photomicrograph of sample $\mathrm{AM} / 2$, which is loaded with the cavity and pores (black region). The white part shows the iron and the dark part is the cavity under the backscattered mode of FE-SEM. Figure $5 c$ shows the cluster of very fine bright dendrites, wüstite, which are also reported in the available literature ${ }^{8,36}$. Wüstite phases are commonly available in the iron slag of the bloomery process. Prokop and Suliga ${ }^{8}$ studied the iron slag from Meghalaya, North East India, and showed that wüstite is present as an acid product for the bloomery iron-making process. In general, the production of iron from its ore produces iron, steel and slag during smelting. The steel and iron are extracted and used locally or traded to far-off places, whereas slags are abandoned near the smelting sites. The slag with the wüstite phase also signifies the microstructure from the bloomery process. The slag is loaded with various voids and a very fine structure of wüstite, and rapidly cools during smelting. Figure $5 d$ reveals the microstructure of iron slag for sample $\mathrm{VM} / 1$ with iron- and silica-rich phase in slag.

Detailed analysis of the iron matrix and secondary phases was done using the EDX technique attached to FE-SEM. Figure $6 a$ shows the SEM micrograph for the AM/1 samples and the EDX spectrum is measured on the slag (dark region) in the micrograph. The slag is rich in metals and non-metals, including iron, which is shown in the inset table. Figure $6 b$ shows the chemical composition of the iron matrix (sample AM/1) free from inclusions. The composition shows the product is made of high carbon steel followed by the carburization process. The specimens are generally heat-treated in the presence of charcoal to improve the strength of the surface of the product. Therefore, the percentage of carbon is relatively higher than steel. It is also observed that the lack of brittleness shows that the product is not made of cast iron, and therefore it is suitable for weapons like axe and sword. Figure $6 c-e$ shows the EDX map, including the $\mathrm{wt} \%$ of elements inside the slag for $\mathrm{AM} / 2, \mathrm{AM} / 3$ and $\mathrm{VM} / 1$ respectively. The analysis shows the slag includes various acidic products like silica and aluminium. These are mainly observed inside the steel slag, as illustrated in the literature ${ }^{35}$. It is also observed from the elemental composition and EDX map that the percentage of iron is very high inside the iron slag. The bloomery process during ancient metallurgy was not advanced, and therefore a very high amount of iron remained with the slag.

\section{Mechanical analysis}

The Vickers microhardness for the samples was measured and is plotted in Figure 7 with the indentation micrograph for each sample. The indentation area for sample AM/1 is much more compared to that for the rest of the samples.
The size of the indent, as shown in the Figure 7 inset, decreases with increase in hardness, which is also observed in the hardness plot. It is observed that the structure of slags is highly non-homogeneous and reveals a metal-slag composite structure. Therefore, the value of
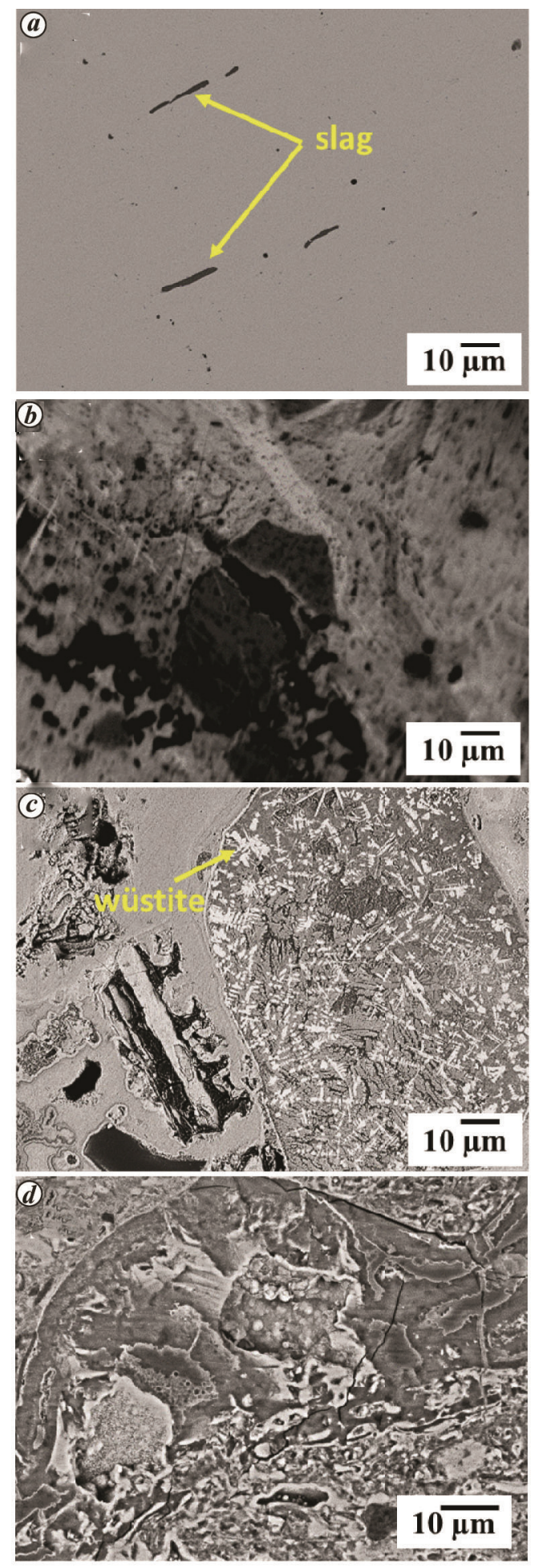

Figure 5. The microstructure before etch condition for (a) AM/1, (b) $\mathrm{AM} / 2,(\boldsymbol{c}) \mathrm{AM} / 3$ and $(\boldsymbol{d}) \mathrm{VM} / 1$ 
RESEARCH ARTICLES
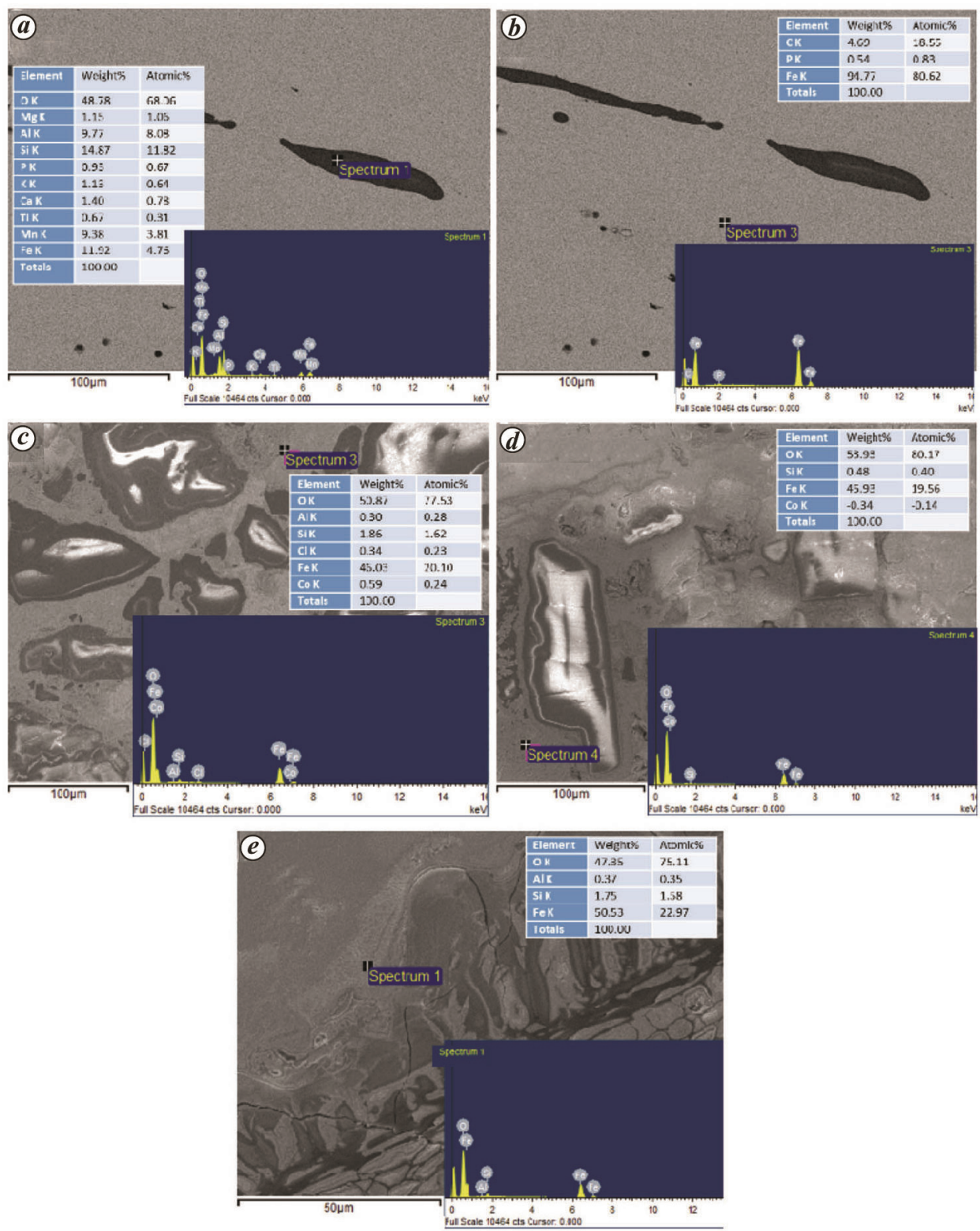

Figure 6. The microstructure and EDX report before etch condition for (a) AM/1 slag, (b) AM/1 matrix, (c) AM/2, (d) AM/3 and (e) VM/1

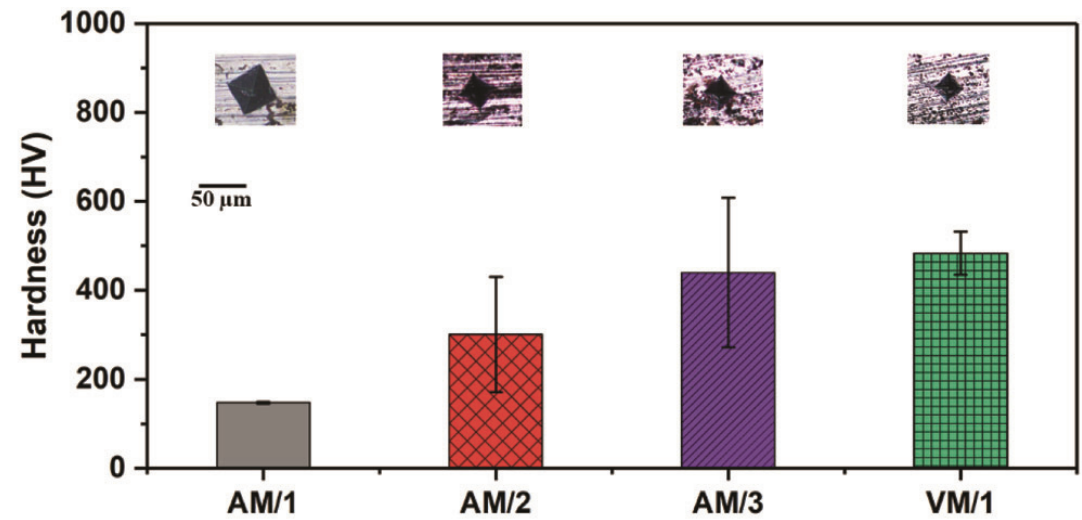

Figure 7. Vickers hardness value, including microstructure of indent for different samples. 
micro-hardness for the slags tremendously varied from the standard deviation and showed a relatively higher value of hardness than the high carbon steel sample (AM/1).

\section{Conclusion}

The iron objects collected from two different sites, viz. Ambal and Vallam in Tamil Nadu, dated mid-1st millennium $\mathrm{BCE}$ to 10 th $c$. CE and 15 th to 18 th $c$. CE respectively, were analysed using microscopy as well as mechanical and elemental composition characterization techniques. The result shows that the cutting tool (like an axe) was made of high carbon steel, including the heat-treatment process. The study shows that the tradition of steelmaking might have been well established and the inhabitants were fully equipped with smelting and thermo-mechanical processing facilities. It is also observed that analysing a core for characterization yields more accurate results. Generally, microstructures are not identifiable in slags. However, the slags analysed in this study were loaded with substantial non-metallic materials. Thus in the absence of good quality microstructure and hardness data, a definite conclusion regarding the slags would be premature. However, the present study shows evidence of indigenous steelmaking process in southern Tamil Nadu.

These objects were broadly derived from two contexts: one in the Iron Age-early historical context (AM/1) and others in the medieval context. The production of iron in the Iron Age and early historic contexts could be different. The Iron Age society was predominantly agropastoral, and the implements were produced for agrarian and defence purposes. These samples are from habitation sites, and the Iron Age-early historical sample was part of a craft system that was producing artifacts for the community involved in agrarian operations and also in wars, and is closer to the megalithic cult tradition. The Sangam Tamil poems discuss iron technology and refer to the importance of iron swords in various battles. Thus the iron crafting tradition of the Iron Age-early historic period was in the context of warring communities. However, in medieval times different types of iron production took place; while the medieval kings were involved in battles, they required iron swords; but in household and day-to-day contexts, people used iron objects for construction and other activities. The objects from medieval contexts were mostly from nail fragments. The iron nails produced for construction would be used only once, and hence they would be of different quality. However, the implements used for cutting as part of agrarian and pastoral and battle purposes would have been prepared with care. This might explain the nature of the iron objects presented in the two groups of samples discussed here. However, this needs to be tested by collecting various objects of functional categories from the Iron Age to the medieval period to understand how functional categories determined the production patterns.

Declaration of interest: The authors declare no competing financial interest.

1. Balasubramaniam, R. and Prabhakar, V. N., On technical analysis of characters of the oldest Delhi Iron Pillar inscription. Curr. Sci., 2007, 92, 1709-1719.

2. Srinivasan, S. and Ranganathan, S., Wootz steel: an advanced material of the ancient world. Iron Steel Herit. India, 1997, 69-82.

3. Ghosh, A. and Panigrahi, K. C., Pottery of Ahichchatra (UP). Anc. India, 1946, 1, 37-59.

4. Gordon, D. H., Excavations at Hastinapura and other explorations in the upper Ganga and Sutlej basins, 1950-52. By B. B. Lal. pp. 151, 73 plates, 37 figs. Ancient India, Bulletin of the Archaeological Survey of India, Nos. 10 and 11, 1954-5. Price (complete number) Rs 9 to 14s. Antiquity, 1957.

5. Voysey, H. W., Description of the manufacture of steel in Southern India. J. Asiat. Soc. Bengal, 1832, 1, 245-247.

6. Sasisekaran, B., Metallurgy and metal industry in ancient Tamil $\mathrm{Nadu}$ - an archaeological study. Indian J. Hist. Sci., 2002, 37, 1729.

7. Srinivasan, S., Indian iron and steel, with special reference to southern India. World Iron, 2013, 83-90.

8. Prokop, P. and Suliga, I., Two thousand years of iron smelting in the Khasi Hills, Meghalaya, North East India. Curr. Sci., 2013, 104, 761-768.

9. David, N., Heimann, R., Killick, D., and Wayman, M., Between bloomery and blast furnace: Mafa iron-smelting technology in North Cameroon. Afr. Archaeol. Rev., 1989, 7, 183-208.

10. Srinivasan, S. and Ranganathan, S., The Significance of Wootz Steel to the History of Materials Science, 2011.

11. Selvakumar, V., Archaeological of the Lower Kaveri Valley: Excavation at Ambal, Nagapattinam District, Tamil Nādu, 201516. Unpubl. Rep., 2020, 21-48.

12. Banerjee, N. R., The Iron Age in India. Ph D thesis, University of Calcutta, 1962.

13. Chakrabarti, D., The beginning of iron in India. Antiquity, 1976.

14. Shaffer, J. G., The Indo-Aryan invasions: cultural myth and archaeological reality. In The People of South Asia People South Asia, Springer, Boston, MA, 1984.

15. Tewari, R., The origins of iron-working in India: new evidence from the Central Ganga Plain and the Eastern Vindhyas. AntiquityOxford, 2003, 77, 536-545.

16. Uesugi, A., An overview on the Iron Age in South Asia. In International Symposium on the Iron Age in South Asia Osaka, 2018, pp. 3-9.

17. Jaikishan, S. and Balasubramaniam, R., Evidences for wootz steel in Northern Telangana - S Jaikishan \& R Balasubramaniam.pdf. Indian J. Hist. Sci., 2007, 42, 461-480.

18. Selvakumar, V. et al., Iron Age-Early Historic and Iron Age-Early Historic and Medieval Settlements in the Lower Kaveri Valley: a preliminary report of the Archaeological Excavation at Ambal (2015-16), Nagapattinam District, Tamil Nadu. Puratattva, 2016, 46, 168-174.

19. Johansen, P. G. and Bauer, A. M., Beyond culture history at Maski: land use, settlement and social differences in Neolithic through Medieval South India. Archaeol. Res. Asia, 2015, 1, 6-16.

20. Park, J. S., Rajan, K. and Ramesh, R., High-carbon steel and ancient sword-making as observed in a double-edged sword from an Iron Age megalithic burial in Tamil Nadu, India. Archaeometry, 2020, 62, 68-80.

21. Wadsworth, J. and Sherby, O. D., On the Bulat-Damascus steels revisited. Prog. Mater. Sci., 1980, 25, 35-68. 
22. Verhoeven, J., Pattern formation in wootz Damascus steel swords and blades. Indian J. Hist. Sci., 2007, 42(4), 559-574.

23. Juleff, G., An ancient wind-powered iron smelting technology in Sri Lanka. Nature, 1996, 379, 60-63.

24. Selvakumar, V., Archaeology of the Lower Kaviri Delta, on the East Coast of Tamil Nadu: Early Historic Settlement System, 2007.

25. Selvakumar, V., Sangam Age Settlements of Punalnaatu or Kaviri Naatu, 2010.

26. Selvakumar, V., Buddhism and Devaara Temples in the Lower Kaveri Valley. In Lecture Delivered at the 10th Annual Meeting of the Tamil Heritage Foundation, Chennai, 2011.

27. Suresh, S., Nannilam Vattarath Tholliyal, Tamil University, Thanjavur, Tamil Nadu, 2008.

28. Rajan, K. and Ramji, M. S., Palaeolithie sites in Kaveri River Valley of Ariyalur Region, Tamil Nadu. Man Environ., 2009, XXXIV, No. 29.

29. Selvakumar, V., Rajaguru, S. N. and Jhaldiyal, R., Palaeolithic occupation of southern Tamil Nadu, India: new evidence from south of the river Kaveri. Quat. Int., 2012, 269, 74-86.

30. Sailesh, M., Kaveri-Arasalarruppaguthiyin Varalaarum Tholliyalum, Tamil University, Thanjavur, Tamil Nadu, 2013.

31. Gayathri, C. R., Recent Archaeological findings in Tiruvarur region. In 25th Annual Meetings of Tamil Nadu Archaeological Society, Rajapalayam, 2015.

32. Selvakumar, V., History of numbers and fractions and arithmetic calculations in the Tamil region: some observations. HuSS Int. J. Res. Humanit. Soc. Sci., 2016, 3, 27.
33. Subbarayalu, Y., An aspect of the revenue system of the Cholas. Proc. Indian Hist. Congr., 1984, 45, 172-176.

34. Sukhanov, D. A. and Plotnikova, N. V., Mechanical properties of xviii century Persian Bulat Steel compared with modern tool steels. Metallurgist, 2020, 63, 1192-1203.

35. Park, J. S. and Rehren, T., Large-scale 2nd to 3rd century AD bloomery iron smelting in Korea. J. Archaeol. Sci., 2011, 38, 1180-1190.

36. Selskienè, A., Examination of smelting and smithing slags formed in bloomery iron-making process. Chemija, 2007, 18, 22-28.

ACKNOWLEDGEMENTS. We thank the Science and Engineering Research Board (project number CRG/2018/004944), Board of Research in Nuclear Sciences (project number 57/14/05/2019-BRNS), University Grants Commission and Indian Council of Historical Research for financial support. We also thank Rajat Mishra (Indian Institute of Technology, Gandhinagar (IITGN)) for help with sampling and documentation, IITGN for providing the necessary facilities and the library staff of IITGN for making the required literature available on time.

Received 27 April 2021; accepted 20 May 2021

doi: $10.18520 / \mathrm{cs} / \mathrm{v} 121 / \mathrm{i} 2 / 239-247$ 